\title{
GASTÃO CRULS - TRAÇOS DE GÓTICO, BRASILIDADE E NEOFANTÁSTICO NA LITERATURA BRASILEIRA?
}

\section{GASTÃO CRULS - TRACES OF GOTHIC, BRASILIDADE AND NEOFANTASTIC IN BRAZILIAN LITERATURE?}

\author{
Francisco Javier Sánchez-Verdejo Pérez ${ }^{1}$, Filomena Fernandes Gonçalves²
}

\begin{abstract}
RESUMO: $O$ romance Frankenstein ou o Prometeu Moderno, escrito por Mary W. Shelley e publicado originalmente em 1818, tornou-se numa das obras basilares do imaginário góticofantástico, graças a inúmeras versões deste relato, quer no continente europeu, quer no continente americano, tanto na literatura, como no cinema e no teatro. O presente artigo tem como objetivo refletir sobre o modo como, em três dos seus contos, "Noites brancas" (1920), "No embalo da rede"(1923) e "O Espelho"(1938), o autor de vanguarda Gastão Cruls apresenta uma nova leitura do Gótico e se apresenta como precursor brasileiro do Neofantástico. Partindo da premissa de que o texto literário crulsiano ainda está a ser descoberto no meio académico europeu, este trabalho analisa os mecanismos literários com os quais Gastão Cruls desencadeia reações de medo, pasmo, suspense, insólito ou logro no leitor.
\end{abstract}

PALAVRAS-CHAVE: brasilidade; gótico; neofantástico; Gastão Cruls

ABSTRACT: The novel Frankenstein, or The Modern Prometheus, written by Mary $W$. Shelley, and originally published in 1818, has become one of the most influential works in the Gothic-Fantastic imaginary, mainly for the many versions of this genre, both in Europe and in America, in literature and cinema, as well as in drama. This investigation aims to analyze the means how, in three short stories, "Noites brancas" (1920), "No embalo da rede" (1923) $e$ "O Espelho" (1938) the avant-garde author, Gastão Cruls, revisits the traditional European Gothic and may be considered as a Brasilian predecessor of Neo-Fantastic. Assuming that the literary text from Cruls is still being discovered and yet to be studied in Europe, this article analyzes the literary mechanisms Gastão Cruls uses to create reactions of fear, astonishment, suspense, unusual, or deceive in the reader.

KEYWORDS: brasilidade; gothic; neo-fantastic; Gastão Cruls

\footnotetext{
${ }^{1}$ Ph. D. Universidad de Castilla-La Mancha Facultad de Letras: Ciudad Real, Castilla-La Mancha, ES. Department of Foreign Languages and their Philologies - National Distance Teaching University - ES.

${ }^{2}$ Mestre em Literaturas e Culturas Modernas, Departamento de Lingüística da Universidade Nova de Lisboa (UNL) (Portugal).
} 


\section{Introdução.}

O texto de Mary Shelley, Frankenstein ou o Prometeu Moderno, onde é evidente a angústia e inquietação da criatura criada pela personagem Victor, serve de inspiração a Gastão Cruls. No discurso deste autor brasileiro de origem belga é visível, igualmente, o espetro da primeira Guerra Mundial, que constitui o primeiro momento na História da Humanidade em que o pensamento científico é usado para fabricar armas de extermínio massivo de seres humanos (DEBEHOGNE, H. \& De FREITAS MOURÃO, 1978; ANDRADE, 1988). Porém, se no romance de Shelley, ao invés de se destruir, parece, aparentemente, criar-se um novo ser, o seu criador, o cientista, manifesta marcas de uma tendência criadora destrutiva.

Neste contexto, o pensamento científico, associado à angústia existencial, marcam a obra de Cruls. Se é óbvia a proximidade com Shelley na relação de ambos com a ciência, em Cruls é visível a exploração da temática do dualismo humano, da dissociação da personalidade, da presença do narrador autodiegético, quase (ou não) bipolar, manipulado e manipulador (MAIA VILELA, 2012). São igualmente claras as semelhanças entre esta escrita e a de Robert Louis Stevenson, em O estranho caso de Dr. Jekyll e Mr. Hyde (1886). Aqui se vislumbra um vasto e interessante campo de estudo, que anuncia uma relação intencional com a psicanálise, com uma nova visão estética do narrador e, acima de tudo, com o papel fulcral do leitor moderno. Enquanto recetor da obra literária e/ou criador de outra narração, face às expectativas que o narrador lhe cria e/ou vítima da narrativa manipuladora da intriga, através de jogos de fantasmagoria e da criação do efeito de espelho que extrapolam o texto e interferem com o perfil literário, psicológico e contextual, o leitor - que não é alheio ao medo/terror/fascínio por si próprio - redescobre-se e vislumbra-se, exposta a sua fragilidade e monstruosidade. Acima de tudo, revela-se capaz de imaginar/construir a ideia de terror e dela retirar prazer, para que muito contribui a escolha da palavra, da frase e da pontuação de sentido subjetivo. Neste sentido, decidimos tomar como ponto de partida a análise detalhada de três dos seus contos mais marcantes, "Noites brancas" (1920), "No embalo da rede" (1923) e "O espelho" (1938).

Partiremos de três pólos orientadores, o Gótico, a Brasilidade e o Neofantástico, quer enquanto marcas literárias, quer enquanto características dos textos de Gastão Cruls.

Procuraremos demonstrar que estes textos, ora em estudo, apresentam especificidades próprias que, se por um lado os aproximam de algumas das características do Gótico 
(PUNTER, 1980; BOTTING, 1997; MONTEIRO, 2004), essas não constituem por si só, fundamento para considerar Gastão Cruls como um escritor gótico.

Por outro lado, observaremos como, na escrita deste autor, podemos observar marcas que a identificam com o contexto brasileiro, quer no que diz respeito ao léxico utilizado, quer nas referências aos espaços da América do Sul que servem de cenário à ação de cada conto, quer ainda aos aspetos culturais a ele inerentes, como sucede, por exemplo, com os trâmites que estão relacionados com os velórios no Sertão, ou os leilões no Rio de Janeiro. Este aspeto leva-nos a associar os textos de Gastão Cruls, ora em estudo, com o que designaremos por Brasilidade (RODRIGUES FILHO, 2005, p. 344). Com este termo, pretendemos referir-nos àquilo que distingue os hábitos e costumes do Brasil do resto da América Latina e dos povos que poderão ter passado por este território, como o foram os portugueses e os holandeses.

Por último, demonstraremos que há marcas de vanguardismo nos contos referidos, os quais poderiam tornar Gastão Cruls um dos precursores do Neofantástico na Literatura Brasileira, termo usado por Jaime Alazraki, escritor argentino, mais tarde.

\section{O Gótico e Cruls}

Sem nos querermos debruçar detalhadamente sobre as características, sobejamente estudadas, que distinguem o Gótico no universo da Literatura Fantástica. Se há uma presença do gótico de inspiração europeia e norte-americana em Cruls (FRANÇA, 2013), também é inegável que este autor faz dele uma leitura peculiar e mais criativa. A escrita de Cruls está impregnada de brasilidade, presente na construção da personagem feminina (que se descola da sua homónima gótica, para se destacar pela sua faceta amazónica); nas referências culturais às fazendas, aos coronéis, ao Sertão, à Amazónia (sensual, insinuante, diabólica e transfiguradora) (COELHO PAIVA, 2019; LIMA e COSTA JUNIOR, 2011, p, 221-237); ao final que já não repõe a ordem inicial da narrativa (mas que a torna ainda mais perturbadora); à referência à doença típica do Brasil (por exemplo, a borreliose); à distopia; à dissecação da psiqué humana; e à visão disruptiva e por vezes herética da religião europeia - o catolicismo (pela violação das normas cristãs do colonizador europeu quanto à sexualidade, ao papel da mulher e à relação de forças políticas, sociais e sexuais (SILVEIRA MAIA, 2009). De facto, aqui encontramos ecos de Wells, de Poe, de Shelley, de Stoker, mas, acima de tudo, encontramos uma nova voz literária que pretende trazer sobre ele um novo olhar e deixar um contributo inovador à Literatura Fantástica (MELO e CASTRO, 1974). 


\section{Evidências do Gótico nos contos em análise}

Ao leitor mais atento destes contos, não passarão despercebidas as referências a características do Gótico, no texto de Gastão Cruls.

No que diz respeito à temática da loucura e da devassidão sexual nestes contos de Gastão Cruls, quando a personagem de "Ao embalo da rede", Otávio Barros, afirma "ainda não mereço a cadeia ou o hospício, conquanto a minha observação já deva andar por aí, na mão de alguns médicos, para figurar mais tarde em qualquer tratado de psicologia" (CRULS, 1952, p. 217), é óbvia a aceitação e consciência dos estranhos comportamentos, que situam a personagem no limiar do que é a considerada sanidade mental. $\mathrm{O}$ mesmo sucede no conto " $\mathrm{O}$ espelho", com a figura masculina, o narrador-marido de Isa. Neste outro relato breve, este facto aproxima-o, todavia, de uma visão patológica sobre os seus comportamentos, que lembra o conto de Edgar Alan Poe "O coração delator", cuja personagem principal atribui a culpa pelos últimos homicídios por si cometidos ao coração da sua primeira vítima, que ele escondera debaixo do chão da sala, e que insistia em ouvir bater.

Quanto à temática da deformação/decomposição do corpo (FRANÇA, 2018, p. 873887), em Cruls a reação de repulsa é ampliada pelo facto de que aqui encontramos figuras muito mais asquerosas e repugnantes que as que povoam outros textos góticos. Mais do que a repulsa e o nojo que as descrições expressivas crulsianas possam provocar no leitor, é de ressaltar a monstruosidade das personagens, que, aqui, aparentam a normalidade física - ou melhor, se descrevem até como sendo decentes, charmosas, elegantes, bem educadas -, que se nos revelam, afinal, autenticamente monstruosas, traço que encontramos nos três contos em estudo. Aquilo que os românticos acentuavam como elemento que despoleta o medo e o terror (PUNTER, 1980; BOTTING, 1997) é o que nas narrativas breves de Cruls menos surge valorizado, sendo apenas a partir das confissões secretas das personagens que as passamos a ver com horror e medo. Parece, portanto, evidente, que Cruls pretendia traçar retratos psicológico-psiquiátricos que remetessem para a visão aterradora do homem que parece o que não é, e que é o que não parece.

\section{O uso das reflexões sobre o poder}


Não deixa de ser aliciante debruçarmo-nos sobre a visão daquilo que nos parece ser, em um herdeiro do colonialismo europeu no Brasil, o imperialismo interno brasileiro. Nos textos de Gastão Cruls, encontramos retratos detalhados e críticos das fazendas e dos coronéis do Sertão, referências subliminares, tanto ao papel da mulher brasileira perante a autoridade masculina sobre si exercida, como à figura da mulher no contexto amazónico, e, por último, à representação da sexualidade feminina, perante um aparente poder sexual masculino (ANDRADE, 1988; Da MATTA VIVOLO, 2013; FRANÇA, 2013). Em todo o caso, porém, conseguimos vislumbrar uma forma de estar mais europeia que autóctone, quer pelas referências aos objetos da casa (o espelho barroco com figuras mitológicas gregas, por exemplo), quer pelas atividades levadas a cabo pelas personagens, de classe social mais elevada, que viajam pela Europa, se dedicam ao ócio ou compram bric-à-brac. Por outro lado, se nos focamos nas reflexões sobre o poder que caracterizam o Gótico, é de salientar a originalidade de Cruls, ao trabalhar o papel da mulher neste contexto. Com efeito, a personagem feminina de Cruls é vista de uma forma bastante distinta da mulher gótica. Face à autoridade masculina que caracteriza a sociedade brasileira do tempo da narrativa, a mulher crulsiana é um misto de mulher-anjo tutelar, que protege e cuida da família e do marido (D. Clarice, por exemplo, em "Noites brancas"), de mulher sensual e erótica (tal como sucede com Isa, de "O espelho"), de um ser mais vampírico, noturno, luxurioso e insaciável - quase animalesco - que elege, caça e se serve sexualmente do seu parceiro (como sucede em "Noites brancas", com a personagem Maria Clara ou, talvez com menos expressão, D. Alzira, em "Ao embalo da rede").

\section{As referências à noite}

Uma das características góticas que mais se destaca nestas narrativas é o tema da noite (PUNTER, 1980; BOTTING, 1997). Nos contos de Cruls, encontramos tanto as referências à noite, como ao luar. $\mathrm{O}$ ambiente noturno fechado, por vezes claustrofóbico, surge em todos os contos ora em estudo. Em “Ao embalo da rede”, por exemplo, o narrador alude ao espaço em que "mal se podia respirar", tanto pelos odores a cadáver, como pelo calor. Em "O espelho", por sua vez, encontramos variadas referências à noite, quer enquanto momento propício ao erotismo, facilitado pelo consumo de álcool e "outros estimulantes ainda mais nocivos", quer pelo efeito de fantasmagoria provocado pelo espelho, que desencadeiam comportamentos sexuais mais desprovidos de pudor. O mesmo sucede em "Noites brancas", cujo título por si 
só já reforça o que afirmamos e em que as duas citações iniciais, uma de Maurice Magre e outra de Octave Mirbeau, remetem para a luta interior entre o desejo carnal e a razão, entre o lado instintivo e animalesco do homem e a sua faceta racional, que o leva a temer ceder à carne (ambas a deixarem entrever a dissecação da mente humana). E não podemos deixar de aludir à expressão tão gótica com que Carlos aqui se refere à sua "visitante noturna", anónima, misteriosa e também por isso, mais sensual.

Por outro lado, ora surgindo como elemento transfigurador dos espaços e das personagens, ora cumprindo a função de revelar o que estava escondido/velado, o luar é uma das marcas góticas que atravessa os três textos em análise. Em "Noites brancas", este efeito torna-se ainda mais evidente, já que é numa noite de luar que Maria Clara deixa de visitar o narrador.

\section{Cruls - escritor gótico ou precursor do neofantástico?}

Com efeito, e ainda que sejam visíveis características góticas na escrita de Cruls, estas não nos parecem ser suficientes para considerarmos que este escritor é gótico. Para justificar a nossa interpretação destes textos, à luz do gótico, convém observar que eles carecem de algumas das marcas apontadas pelos estudiosos na matéria como basilares para a inserção de um texto nesta categoria literária. De facto, se observamos com mais atenção todo o texto, constataremos, por exemplo, a ausência do sobrenatural nestas narrativas. E se, em Drácula, de Bram Stoker e em Frankenstein, de Mary Shelley, ocorre uma recuperação da ordem natural das coisas, no final da narrativa, isso não sucede nos textos de Cruls que estudamos. Carlos, de "Noites brancas", pensa ter sido contagiado por Maria Clara com a lepra, mas ninguém, a não ser ele próprio, saberá em que circunstâncias a contraiu; Otávio, de "Ao embalo da rede", sente atração por corpos em decomposição, mas ninguém saberá o que despoletou esse facto; e, no caso deste conto, o ato sexual não põe em causa o casamento de D. Alzira, porque ela já estava viúva; já quanto ao seu noivado, Otávio acaba por ajudar a repor uma certa ordem na família da noiva, que o não via com bons olhos para marido da sua parente, por ser ele o "estudantezinho" de origens sociais inferiores às da família dela, o que se nos afigura mais irónico que aplaudível; por fim, a morte de Isa, de "O espelho", e a profanação do seu cadáver, pelo marido, e por causa da sua volúpia, quem as saberá? Há, pois, em todas estas histórias, um final perverso, perturbador, que as afasta do gótico tradicional. Além do que afirmamos, tenhamos ainda em conta que, em nenhum dos três 
contos referidos, há, em algum momento, um sentimento de terror; pelo contrário, são frequentes as alusões à serenidade das personagens e dos espaços, o que não sucede no texto gótico, cujo cenário, por ser decadente, estar em ruína ou abandonado suscita o medo (FRANÇA, 2013). Para mais, tampouco constatamos a presença de elementos animais associados ao noturno, ao mau agouro ou à fealdade, que sempre se evocam no texto gótico.

Por fim, lembremo-nos de que Gastão Cruls foi considerado como um escritor menor pelos seus pares (MELLO, 1959, p. 211-222.) e, em nossa opinião, talvez esta nomeação tenha muito do facto de ele se ter desviado - cremos, intencionalmente - dessas tradicionais normas literárias (SILVEIRA MAIA, 2005). Para nós, esta, que poderia ser uma marca de menor qualidade do seu texto literário, é precisamente, o mais importante traço da sua escrita.

O que queremos dizer é que, se Cruls não tivesse violado as regras do texto gótico, não o veríamos agora como eventual precursor do que Jaime Alazraki (1934-2014) viria mais tarde a chamar de "Neofantástico".

\section{O conto neofantástico - uma proposta de definição e caracterização}

A questão que subjaz à definição e aparecimento do Neofantástico prende-se com a necessidade de prover resposta à dificuldade de definir algumas narrativas que, apesar do seu pendor indiscutivelmente fantástico, prescindem dos génios do maravilhoso, do horror do conto, ou da tecnologia de ficção científica (MEIRELLES da SILVA, 2008). Aqui se situam os textos de Edgar Alan Poe, Jorge Luís Borges e Júlio Cortázar, por exemplo. Com efeito, é Cortázar quem afirma que: "Para mi, lo fantástico es algo muy simples, que puede suceder en plena realidad cotidiana, en este mediodía de sol, ahora, entre Ud. y yo, o en el Métro, mientras Ud. venía a esta entrevista” (ALAZRAKI, 1990, p. 27).

Além disso, e ao passo que Caillois defende que o fantástico supõe a solidez do mundo real, mas para poder devastá-lo, e que, para H.P. Lovecraft, um conto só é fantástico se o leitor experimentar profundamente um sentimento de temor e de terror e pressentir a presença de mundos e poderes insólitos, para Jaime Alazraki, nestas definições não cabe a visão desprovida do transcendente, do teológico e do cultural que caracterizam a realidade. Para tornar mais clara a lacuna que Alazraki aponta ao fantástico, tal como Todorov (1975) o define - e o encontramos nos textos de Caillois e de Lovecraft-, veja-se como explica Cortázar a visão da realidade inédita, todavia, uma realidade "maravilhosa" aludida no seguinte excerto: 
(...) en el sentido de que la realidad cotidiana enmascara una segunda realidad que no es ni misteriosa, ni transcendente, ni teológica, sino que es profundamente humana, pero por una serie de equivocaciones ha quedado como enmascarada detrás de una realidad prefabricada con muchos años de cultura en la que hay maravillas pero también profundas aberraciones, profundas tergiversaciones (GARCÍA FLORES, 2005, p. 10-11).

Por outro lado, o conto moderno, tal como o entendemos, difere da conceção, organização e funcionamento das formas que o precedem. É com Edgar Alan Poe que o relato breve adquire uma tessitura, concentração e estrutura que não tinham os seus precursores. Segundo Jaime Alazraki, Poe define, não apenas o peculiar da sua extensão - texto que se lê de uma assentada-, mas também outros traços distintivos, como por exemplo, o efeito singular que controla e determina a disposição do argumento, que fixa a composição do texto e que estabelece interrelações entre as suas partes. Tal como afirma Cifuentes:

Se trata de una escritura de la "intensidad" más que de la "extensidad" lo que justifica que se haya fijado mayormente en el género corto, pues la brevedad, la intensidad y el enigma comparten el sema de lo fragmentario o discontinuo. Lo breve es lo corto, lo intenso, lo que no se extiende, pues es la sima de un continuum, y, el enigma - cuyo fin es dificultar la comprensión de su mensaje — si se extiende se explica, (puesto que el sentido etimológico de explicar es desplegar, por lo cual, en un gesto inverso, de repliegue, el enigma también queda circunscrito a lo fragmentario y discontinuo) (CIFUENTES, 2008, p. 229).

Deste modo, o Neofantástico caracteriza-se por uma visão, intenção, modus operandi e contexto próprios. Nele, valoriza-se a ambiguidade, a metamorfose, o ruído e o silêncio, enquanto utensílios de que se serve o texto (CIFUENTES ALDUNATE, 2008).

Em primeiro lugar, e quanto à sua visão, o neofantástico assume o mundo real como uma máscara, que oculta uma segunda realidade, que é o verdadeiro destinatário deste tipo de narração. A realidade é, nela, "una esponja, un queso gruyere, una superficie llena de agujeros como un colador y desde cuyos orificios se podía atisbar, como en un fogonazo, esa otra realidad.”, tal como Alazraki o afirma, citando Johnny Carter (ALAZRAKI, 1990, p. 29).

Em segundo lugar, já no que diz respeito à sua intenção, com o Neofantástico, o que se pretende não é provocar nem o medo, nem o terror no leitor, no qual tropeçam os seus pressupostos lógicos. Pretende-se, sim, produzir perplexidade e inquietação no leitor, pelo insólito das situações narradas. O mundo real apresenta-se, aqui, na sua faceta opaca, ilegível, caótica, a lembrar a Biblioteca de Babel, de Jorge Luís Borges, de livros também, mas estes, ilegíveis e, portanto, indecifráveis, logo, mais aliciantes (ALAZRAKI, 1990, p. 29). 
Além disso, no texto neofantástico, o ruído e o silêncio, a ambiguidade e a metamorfose permitem uma multiplicidade de interpretações, que são alheias ao próprio conto.

Já quanto ao modus operandi destas narrações, o texto neofantástico distancia-se consideravelmente do conto fantástico, uma vez que o primeiro prescinde dos bastidores e ferramentas que contribuem para a atmosfera de pathos, necessária para a desmontagem final no segundo. O texto neofantástico introduz-nos, pois, desde as primeiras frases da narrativa no elemento fantástico. Contudo, ao passo que este se move no plano do literal, o neofantástico alude a sentidos oblíquos ou metafóricos, ou ainda figurativos.

Por sua vez, o contexto em que se situa o neofantástico é, também, díspar daquele que encontramos no fantástico. Se o conto fantástico é contemporâneo do movimento romântico, questionando e desafiando o racionalismo científico e os valores da sociedade burguesa, a narrativa neofantástica é respaldada pelos efeitos da Primeira Guerra Mundial, pelos movimentos de vanguarda entretanto surgidos, por Freud, pela psicanálise, pelo surrealismo e pelo existencialismo.

Por último, e quanto ao uso do vocábulo Neofantástico, é Alazraki quem a este termo recorre, perante a impossibilidade de denominar com outro a sua visão do que este subgénero implica:

Propuse la denominación neofantástico como un llamado de atención de las diferencias que he señalado entre esos dos tipos de narración. También porque la toma de consciencia de esas diferencias permitiría una mejor comprensión de los sentidos y alcances del nuevo género y un estudio más cabal y concienzudo de sus textos. La vaguedad nunca ha sido beneficiosa para el estudio de la literatura. "Las especificidades nos ayudan mucho más que las generalidades", advertió en una ocasión Harry Levin (ALAZRAKI, 1990, p. 31).

Todavia, talvez sejam as próprias palavras de Júlio Cortázar, pouco antes da sua morte, em entrevista com Omar Prego, que legitimam, de uma forma mais consistente, o uso do termo, para fissurar a definição tradicional do que se designa por "literatura fantástica":

Julio Cortázar: mi sentimiento de lo fantástico, lo que tal vez Alazraki llama neofantástico... no es un fantástico... como el fantástico de la literatura gótica, en que se inventa un aparato de fantasmas, de aparecidos, toda una máquina de terror que se opone a las leyes naturales, que influye em el destino de los personajes. No, claro, lo fantástico moderno es muy diferente (ALAZRAKI, 1990, p. 32).

Em suma, o Neofantástico não constitui uma nova escola literária, per si, mas insere- 
se num género literário já existente, de que se assume como variante.

\section{Evidências do neofantástico nos contos de Cruls}

Com efeito, se nos detemos na análise da forma como evolui a narrativa de Cruls, desde que se publica o primeiro destes três contos, em 1920, e o último deles, em 1938, constatamos que este é mais rico em referências literárias e filosóficas. Assim, observamos que, em "Noites brancas", a intriga parece ser ainda muito marcada pela influência do Romantismo inglês e naïf, quanto à construção psicológica das personagens - é de salientar que Carlos, por exemplo, se nos apresenta como a personagem romântica que busca na tranquilidade do campo a paz para convalescer de uma enfermidade, acabando por aí contrair outra, ao passo que as restantes personagens da família Jesus nada saberão, desde o princípio até ao fim da narrativa, do caso amoroso com Maria Clara. Já quando lemos "Ao embalo da rede", de 1923, a própria citação inicial de Guy de Maupassant indicia já um desvio do foco narrativo para as questões da mente, centrando toda a narrativa na visão psiquátrica que se tem dos comportamentos humanos e da forma como esses são (ou não) moldados pelos valores culturais e religiosos. Neste conto, a personagem principal centra a sua narrativa na confissão dos seus gostos sexuais peculiares e do episódio ocorrido com D. Alzira, no Sertão, fazendo do seu confidente o guardião deste segredo. Isto significa que, não havendo aqui o sentimento de culpa, nele está presente a necessidade de passar ao outro o peso de carregar esta macabra descoberta por Otávio do que é Otávio. O que queremos dizer é que este não aguenta guardar apenas para si a descoberta da sua afirmada monstruosidade, mas, ao contrário da personagem de Maupassant, que o passará às folhas do seu diário, aqui essa função é atribuída a outra personagem que, por sua vez, não se sente obrigada a dela guardar segredo, tornando-se o narrador que no-la revela. Por outro lado, mais rica se nos apresenta a construção da personagem no último conto, de 1938. Neste, já não nos surgem conflitos entre o instinto e a razão, já não há a necessidade de recorrer ao segredo para ocultar a verdadeira natureza do homem. Neste conto, de nome tão apropriado, tendo em conta o que se vai narrar, continuamos a ver ausente o sentimento de culpa, que, por isso, escusa a personagem da necessidade de perdão, seja ele religioso ou não. Digamos que o papel de Deus daqui está totalmente ausente, por essa razão, o que não deixa de nos lembrar o futuro Existencialismo ateu, por exemplo, de Sartre, que, por seu lado, será mais visto como condenação a uma liberdade e responsabilidade do homem pelos seus atos e que o obrigava a ter de viver com as 
consequências deles, porque foram escolhas suas. Assim, o narrador deste conto, o marido assassino de Isa, toma a palavra para nos contar a nós, leitores, toda a história. Este facto significa que, agora, o que se pretende é narrar para incomodar, é narrar para colocar o destinatário perante a difícil tarefa de decidir o que fazer com esta informação. Não podemos deixar de lembrar Piscator e Brecht, ainda que com objetivos mais práticos e políticos, mas que também pretendem levar o leitor a não se deixar seduzir pelas palavras, mas antes, a reagir a essas mesmas palavras. Como dizia Brecht, no seu poema "Contra a sedução": Lass dich nicht verführen / Es gibt keine Rückkehr ("Não te deixes seduzir/Não há nenhum retorno". A tradução é nossa).

O facto de nos depararmos com esta evolução na construção das personagens, ao longo de dezoito anos de escrita, legitima a nossa afirmação da presença destas influências externas que Cruls sofreu e que enriquecem o seu discurso, aproximando-o do neofantástico, também ele marcado pelos mesmos acontecimentos e visão literária e filosófica do Homem.

Associada a este facto, a linguagem metafórica e de sentido oblíquo que atravessa todos os três contos contribui para detetar indícios do final insólito que caracteriza cada um deles, mas que não conseguimos descortinar à primeira leitura. Este modus operandi do texto neofantástico obriga a uma nova leitura, para encontrar essas pistas subliminares, que sempre estiveram à frente dos nossos olhos, mas que não conseguimos vislumbrar logo (CIFUENTES, 2008, p. 230).

Esta estratégia discursiva está associada àquela que nos parece ser a mais importante razão para classificar estes textos de mais neofantásticos que góticos, que é o facto de haver uma realidade, aparentemente normal, em todos os contos, que esconde uma outra realidade, mais perturbadora e disruptiva. Se pensarmos nas personagens de todos os contos em estudo, constataremos que elas aparentam uma normalidade e decência irrepreensíveis. Mas constataremos também que os seus segredos são insólitos, macabros e perturbadores, que a verdade não é o que parece. Neste sentido, por exemplo, em "O espelho", o narrador tenta passar uma imagem de decência, ao afirmar "Isso não é móvel para casa de gente séria"; em "Noites brancas", por seu turno, apresenta-se a imagem de uma serenidade aparente, na descrição de uma parte oculta da casa ("Embora a casa fosse bastante ampla e, além das dependências do pavimento térreo, ainda tivesse muitos outros quartos na ala direita do sobrado, que parecia inteiramente desocupada, o Coronel, num requinte de zelo pelo hóspede doente, fizera questão de que Carlos ficasse bem ao alcance de suas vistas"); noutro passo do mesmo conto, passa-se a imagem da respeitabilidade aparente, quando se afirma que "no 
silêncio daquelas paragens, por mais leve que fosse qualquer ruído, um simples ranger de portas, passos abafados no corredor, um sussurro de vozes - tudo seria bastante para despertar a atenção do fazendeiro". Por seu lado, em "Ao embalo da rede", estas aparências levam a um casamento de conveniência que não aconteceu, como se esperaria, não por causa da traição de Otávio com Alzira, mas por razões bastante mais insólitas.

Esta revelação da verdadeira natureza humana deixa-nos perante a questão central dos textos de Cruls - que faremos com esta informação? Enquanto europeus, e se nos lembrarmos dos românticos ingleses, o que haveria a fazer seria esconder; se observarmos os realistas do século XIX, há que querer ver; se olhamos para os textos de Brecht, aquilo que há a fazer é reagir. Estamos convencidos de que, em Cruls, porém, o que há a fazer é saber olhar para o insólito, enquanto faceta do ser humano, que o deixa tão próximo como distante do Bem e do Mal, mas que até estas duas visões da nossa natureza são dúbias e desconcertantes.

Em nossa opinião, o texto produz perplexidade e inquietude pelas situações narradas, o que lembra claramente o efeito de espelho que ajuda a ver para além do que os olhos trazem da realidade que se acredita conhecer.

\section{Conclusão}

Parece-nos claro que, neste autor, importa refletir sobre a nossa condição de seres humanos, que coexistem e partilham espaços comuns, que tentam encontrar explicação para a sua insatisfação, face ao papel inexorável do tempo e da morte, que se descobre na sua verdadeira dimensão de ser que é, ao mesmo tempo malévolo, vítima do mal e de si mesmo. Tentámos chegar a algumas conclusões sobre o modo como Gastão Cruls procede a essa reflexão. Nela, encontramos laivos de Gótico, de Brasilidade e de Neofantástico.

No que ao Gótico diz respeito, muitas são as referências a esta manifestação estética. Nos três contos em estudo, encontramos o tema da deterioração física do indivíduo (seja na forma de doença - a lepra, por exemplo), seja nas alusões à morte (com as abundantes referências à decomposição do corpo). Ao mesmo tempo, aqui se sugere, igualmente, uma discussão de ordem política, religiosa e estética, que põe em causa o papel do catolicismo, do colonialismo e dos movimentos estéticos europeus na construção de uma literatura brasileira, no contexto latino-americano. E se, nos textos góticos europeus e americanos encontrávamos o ambiente noturno, claustrofóbico, a servir de contexto espácio-temporal da narrativa, também os encontramos nas palavras de Cruls; porém, aqui não se pretende provocar o terror, 
o suspense ou a atmosfera de mistério, tal como não encontramos a presença do sobrenatural que, para Todorov (1975) distinguia o Fantástico de outras tendências estéticas. Em Cruls, o que encontramos é uma subversão das convenções que marcam o Gótico europeu e americano: agora, nem sempre é uma personagem feminina quem encontramos em perigo (veja-se o caso de Carlos, do conto "Noites brancas"); não há fantasmas, nem vampiros, demónios, espetros ou monstros de aparência aterradora nestes contos - e, contudo, aqui encontramos elementos que são igualmente perturbadores - constatamos a presença de uma mulher quase-fantasma (Maria Clara, de "noites brancas", que vive secretamente numa parte da casa e que aparece apenas na treva da noite), de um monstro disfarçado de uma respeitabilidade que o torna bem mais perigoso e aterrador (o marido psicopata e assassino de Isa), de uma psicologia do horror que, mais que partir do que os olhos veem, explora a devassidão, não da carne, mas da mente humana. Esta surge, muitas vezes, associada à imagem de enorme inteligência do herói, que é frequentemente o elemento que representa o Mal, na narrativa. Lembramos, para exemplo, a forma como Otávio, em "Ao embalo da rede", vai gerindo a revelação, em confidência, do seu lado macabro ao seu amigo: "Eu teria repulsa igual à que leio agora nos teus olhos" - p. 219). Também não encontramos, no texto de Cruls, referências a animais noturnos, feios, sinal de mau presságio; e, todavia, aqui nos surgem a traíra e o curimatã, peixes típicos dos açudes do Sertão, de aspeto algo assustador e, por outro lado, várias referências a animais que, uma vez mais, reforçam a imagem de um espaço sereno, doméstico - os galos, as cigarras, os pássaros —, que esconde o verdadeiro horror dos episódios ocorridos ao abrigo da noite e da solidão de um quarto. As alusões à animalidade humana chegam-nos, ainda assim, e muito obliquamente, quer na presença dos sátiros em " $\mathrm{O}$ espelho", ou dos tigres de Bengala, mencionados em "Ao embalo da rede", ou até na evocação do "par de asas invisíveis" (de cujo animal desconhecemos) e prestes a transportar a personagem de "Noites brancas" para "um mundo irreal e tentador" (p. 66). Mas encontramos, implícita em todas as narrativas, uma referência - muito mais interessante àquela ave trepadora da América Central, que morre quando privada da liberdade, Quetzal, que se manifesta cremos, nalgumas personagens de Cruls - Isa, presa a um casamento monótono, Alzira, condenada ao Sertão, à velhice e à rudeza do Coronel, seu marido, e até em Maria Clara, prisioneira da sua enfermidade e da sua clausura, de que se liberta, suicidandose. A morte sobrevem, pois, vestida de distintas formas, mas sempre, como elemento libertador, ainda que a ele se chegue de forma horripilante. E, se observarmos atentamente, também nelas vislumbramos a serpente azteca, emplumada com penas de quetzal, 
Quetzalcoatl (Quetzalcoatl simbolizava a vida, a abundância da vegetação, o alimento físico e espiritual. Posteriormente, passou a representar a morte e a ressurreição). Não é despropositado este comentário, se pensarmos que, tal como afirma Matta Vivolo, não é difícil encontrarmos "elementos incas e aztecas" nos textos de Cruls, "frutos de sua pesquisa" (MATTA VIVOLO, 2013, p. 76). Aqui, ela aparece sob a forma de luz (estrela da manhã) que revela ou pelo menos nos facilita a tarefa de descobrir a verdadeira essência das outras personagens, que se revelam monstruosas.

Há, pois, nestes contos, algo de catártico, a que se chega através do horror e do insólito. Não podemos, ao mesmo tempo, deixar de referir a presença de variadas alusões ao efeito de horror, conseguido nas alusões a corpos putrefactos, ao sangue, ao döppelgänger, à loucura, aos tabus sexuais quebrados, presentes em todos os contos. Mas há sempre, por parte de Cruls, uma intenção óbvia de não ser tão óbvio nessas alusões; a título de exemplo, refiramos apenas a forma como são violados os tabus sexuais nestes contos. Se neles não encontramos marcas nem de incesto, nem de pedofilia, aqui se narra o ato sexual com um corpo assolado pela lepra, ou ao lado de um corpo putrefacto e em decomposição, ou com um cadáver. Ainda assim, e apesar do que viemos afirmando, pelas razões que apresentamos anteriormente, Cruls não nos parece, portanto, um autor gótico, mas antes um escritor que nos coloca perante uma outra forma de trabalhar o Gótico.

Além do que afirmamos, os textos estudados permitiram-nos, igualmente, detetar muitas marcas do que temos designado de Brasilidade. De facto, nestes contos não foi difícil encontrarmos o retrato dos hábitos severos do Sertão, ou o quotidiano de uma classe endinheirada do Rio de Janeiro, ou a referência a animais e doenças típicas desta zona geográfica, ao seu clima e ao efeito que a Amazónia, enquanto espaço mágico, tem sobre as personagens (MEIRELLES da SILVA, 2010, p. 1-16). As suas divindades e superstições, as referências aos pobres, às mulheres brasileiras, aos empregados, aos estudantes que se sujeitam a casamentos de conveniência como forma de ascensão social, enfim, todos estes aspetos contribuem para apresentar o retrato de um Brasil de princípio de século XX, marcado ainda pelo seu passado colonial, pelas assimetrias sociais, pelos preconceitos e valores ainda próximos de uma Europa colonialista e racista que, já não estando aqui instalada, aqui deixa o seu crivo.

Por último, e ainda que possa parecer arriscado e discutível defender que este escritor apresenta já características vanguardistas (De ANDRADE, 1976) que o aproximam do Neofantástico, esta parece-nos ser a mais-valia do discurso de Gastão Cruls. A verdade é que, 
no retrato de um quotidiano aparentemente normal, Cruls sabe traçar umas pinceladas de insólito, que nos colocam perante o que os olhos não veem, mas a razão sabe. Somos mais do que parecemos ser. Somos uma verdadeira Biblioteca de Babel, se nos observamos pelo nosso lado mental. Quanto a nós, é esse lado que encontramos, nos contos estudados, seja no segredo de um quarto numa casa de um coronel no Sertão, seja num quarto de uma concubina de políticos e argentários, ou no quarto de um casal de aparência decente que frequenta os melhores lugares do Rio de Janeiro. Aqui, não intervêm o transcendente, o sobrenatural, o teológico, não há horror no relato, não há uma tentativa de explicação para os comportamentos narrados. Há apenas a apresentação desses relatos, fria e inócua, ainda que perturbadora. Aqui encontramos o duplo sentido, os indícios, a ambiguidade da palavra e da frase, que não nos deixam, numa primeira leitura, descodificar o seu real e verdadeiro significado (MAIA VILELA, 2012). Há a alusão à metamorfose psicológica, comportamental, espaçial, há a exploração semântica e ideológica do ruído, do silêncio, da palavra que não se diz. E este aspeto prende-se, tanto com a importância desses espaços, quanto com a dos comportamentos e características das personagens que se revelam diante de acontecimentos insólitos, elas próprias insólitas, inexplicáveis, inaceitáveis a si mesmas.

Os textos aludidos afiguram-se-nos, pois, como neofantásticos: na visão que nos apresentam do mundo real como máscara de outro mundo que lhe subjaz e que tentamos ocultar dos outros; na reação de perplexidade que nos fazem ter perante as situações narradas, dando ao leitor uma palavra final a dizer sobre o que se narra; nos silêncios e omissões de palavras e circunstâncias, que nos permitem múltiplas interpretações; no sentido metafórico, oblíquo e figurado que as palavras aqui adquirem; no seu contexto, mais do que espáciotemporal, psicanalítico e acima de tudo psiquiátrico; na extensão breve destes textos, que, por isso e para isso, não explicam tudo, não revelam tudo.

\section{REFERÊNCIAS.}

ALAZRAKI, Jaime. ¿Qué es lo neofantástico?” Mester, v. XIX, n. 2, p. 21-33, 1990.

ANDRADE, Ana Luiza. Gastão Cruls. In: STERN, Irwin (ed.) The Dictionary of Brazilian Literature. New York: Greenwood, 1988.

BORGES, Jorge Luís, O Aleph. Disponível em: 
$<$ https://autoresmodernos.files.wordpress.com/2013/07/borges-jorge-luis-o-aleph.pdf $>$ Acesso em 20 de may. de 2020.

BOTTING, Fred. Gothic. London: Routledge, 1997.

CAILLOIS, Roger. Au Coeur du fantastique. Paris: Gallimard, 1965.

CIFUENTES ALDUNATE, Claudio. De lo fantástico (y neofantástico): sus componentes. In: LÓPEZ PELLISA, Teresa e MORENO SERRANO, Fernando Ángel (eds.) Ensayos sobre ciencia ficción y literatura fantástica: actas del Primer Congreso Internacional de literatura fantástica y ciencia ficción. Madrid: Asociación Cultural Xatafi: Universidad Carlos III de Madrid, 2008. p. 222-231.

COELHO PAIVA, Marco Aurelio. A ordem e a desordem da natureza: o sertão e a Amazônia em Gastão Cruls. Sociologias, v.21, n. 51 Porto Alegre, 2019.

https://doi.org/10.1590/15174522-0215112.

CRULS, Gastão. Contos Reunidos. Rio de Janeiro: José Olympio, 1951.

Da MATTA VIVOLO, Vitor. Gastão Cruls e a auscultação da sociedade brasileira. 2 v. Dissertação de Mestrado. São Paulo: Pontifícia universidade Católica de São Paulo, 2013.

De ANDRADE, Oswald. Manifesto da poesia pau-brasil. In: TELES MENDONÇA, Gilberto (ed.) Vanguarda européia e modernismo brasileiro: apresentação e crítica dos principais manifestos vanguardistas. $3^{\text {a }}$ ed. Brasilia: Petrópolis: Vozes; INL, 1976.

DEBEHOGNE, H. ; De FREITAS MOURÃO, R. R. Un Belge peu connu, Directeur de l' Observatorio Nacional de Rio de Janeiro, est à la Base du Choix de Brasilia. Ciel et Terre, 94, p. $310-311,1978$.

FRANÇA, Júlio. Ecos da Pulp Era no Brasil: o Gótico e o Decadentismo em Gastão Cruls. Terra Roxa e Outras Terras - Revista de Estudos Literários, v. 26, p. 1-130, 2013.

FRANÇA, Júlio. O horror do corpo em dois contos de Gastão Cruls. Gragoatá, Niterói, v. 23, n. 47, p. 873-887, 2018. DOI: http://dx.doi.org/10.22409/gragoata.2018n47a1189.

GARCÍA FLORES, Margarita. Siete respuestas de Julio Cortázar. Revista de la Universidad de México XXI, n. 7, p. 10-13, 1967.

LIMA, Susane Patricia Melo de; COSTA JUNIOR, Waldemir Rodrigues. Geografia e Representação na Amazônia Misteriosa de Gastão Cruls: Da Monocromia à Monotonia, do Fantástico ao Misterioso. Curitiba, UFPR. 2011. p. 221-237.

MAIA VILELA, Marcos António. O fantástico duplo de Edgar Allan Poe e Gastão Cruls. Anais Eletrônicos do IV Seminário Nacional Literatura e Cultura São Cristóvão v. 4. n. 3-4, p 1-114, 2012.

MEIRELLES da SILVA, Alexander (2008) O admirável Mundo Novo da República Velha: o nascimento da ficção científica Brasileira no começo do Século XX. Universidade Federal do Rio de Janeiro. Disponível em: 
<http://www.ciencialit.letras.ufrj.br/pos/trabalhos/2008/alexandermeireles_oadmiravel.pdf $>$. Acesso em 20 de may. de 2020.

MEIRELLES da SILVA, Alexander. A literatura como instrumento de exclusão social em Amazônia Misteriosa, de Gastão Cruls. Revista Eletrônica do Instituto de Humanidades. Universidade Federal de Goiás, p 1-16, 2010.

MELLO, Silvia. Recordações de Gastão Cruls. Revista do Livro v. 4. n. 16, p. 211-222, 1959.

MELO e CASTRO, Ernesto Manuel. (revis., anot. e pref.) Antologia do Conto Fantástico Português, 2. ${ }^{\mathrm{a}}$ ed. Lisboa: Edições Afrodite, 1974.

MONTEIRO, Maria Conceição, Na aurora da modernidade: a ascensão dos romances gótico e cortês na literatura inglesa. Rio de Janeiro: Editora Caetés, 2004.

PREGO, Omar. La fascinación de las palabras: conversaciones con Julio Cortázar. Barcelona: Muchnik, 1985.

PUNTER, David. The Literature of Terror: A History of Gothic Fictions from 1765 to the Present Day. London: Longman, 1980.

RODRIGUES FILHO, José Maria. 'Cobra Norato', de Raul Bopp: a celebração da Brasilidade e as suas possibilidades midiáticas. Forma Breve 3, p. 343-350, 2005.

SILVA, Dayna; AMARAL, Sérgio. Coisas do Outro Mundo: uma leitura do conto 'O Espelho', de Gastão Cruls”. Iniciação Científica, v. 20, n. 2, CESUMAR, p. 193-202, Jul.Dez. 2018.

SILVEIRA MAIA, Cláudio. Gastão Luis Cruls: uma nova recepção. 2 v. Dissertação de Mestrado - Universidade Estadual Paulista (UNESP), Araraquara, 2005.

SILVEIRA MAIA, Cláudio. Pedras Perdidas: o Decadentismo e a Visão Pós-colonial de Gastão Cruls. 2 v. Tese de Doutoramento - UNESP, Araraquara, 2009.

TODOROV, Tzvetan. Introdução à Literatura Fantástica. Trad. de Maria Clara Correa Castello. São Paulo, Editora Perspectiva, [Original: Introduction à la littérature fantastique, Paris, Éditions du Seuil, 1970] e Furtado, Filipe, (1980): A Construção do fantástico na narrativa. Lisboa: Livros Horizonte, 1975.

Recebido em 26/8/2020.

Aceito em 08/01/2020. 